\title{
AVALIAÇÃO DO TRATAMENTO DE ÁGUA GELADA EM AMBIENTE INDUSTRIAL
}

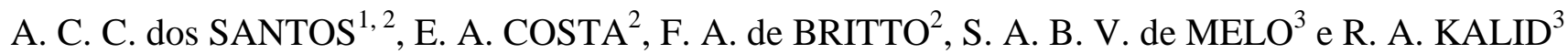 \\ ${ }^{1}$ Instituto Federal da Bahia, Departamento de Processos Industriais e Engenharia Química \\ ${ }^{2}$ Universidade Federal da Bahia, Rede de Tecnologias Limpas - TECLIM \\ ${ }^{3}$ Universidade Federal da Bahia, Programa de Engenharia Industrial \\ E-mail para contato: anacecilia@ifba.edu.br
}

RESUMO - A qualidade das águas é fundamental para o controle do processo, assim como para conhecimento do nível de corrosão e de deposição nos sistemas de aquecimento e resfriamento das plantas industriais. Nesse trabalho avaliou-se um sistema de tratamento de água gelada composto por chillers de uma unidade industrial instalada na Região Metropolitana de SalvadorBA, para estudo dos parâmetros estabelecidos nos limites operacionais, tais como pH, condutividade, concentração de nitrito, ferro total e cloreto. Os resultados das análises da água gelada utilizada para resfriamento do processo durante o ano de 2013 foram comparados com esses limites e indicaram que os parâmetros condutividade e concentração de cloreto estão dentro dos limites de operação, todavia os níveis de $\mathrm{pH}$ apresentam momentos de descontrole. A concentração de ferro total ficou acima dos limites superior indicando a presença de corrosão no sistema. A concentração de nitrito, que é utilizado como inibidor de corrosão, esteve abaixo do limite mínimo necessário, propiciando a corrosão do sistema.

\section{INTRODUÇÃO}

Nos últimos quinze anos, a Rede de Tecnologia Limpas da Bahia (TECLIM), da Universidade Federal de Bahia (UFBA), tem investigado formas de melhorar a eco-eficiência da indústria, edifícios públicos e residenciais desenvolvendo estratégias para a redução da poluição na fonte e metodologias para otimização de processos industriais com foco em produção mais limpa $(\mathrm{P}+\mathrm{L})$, sobretudo nas indústrias da região, de acordo com as exigências de processos mais sustentáveis (Kiperstok et al., 2013).

O objetivo desse trabalho, realizado em parceria com uma unidade industrial da Região Metropolitana de Salvador (RMS), foi avaliar a eficiência do sistema de tratamento da água gelada (AG), comparando as análises físico-químicas com parâmetros de qualidade necessários à operação.

O sistema de produção de AG é composto por: reservatório, bombas centrífugas, tubulações e chiller, sendo este o equipamento mais importante. Apesar de o sistema possuir um circuito fechado, sempre existe a possibilidade de contaminação por sólidos. Segundo Mancuso (2001), várias são as fontes de contaminação, que se dividem em externa e interna. As fontes de contaminação externa se devem principalmente ao material de construção do sistema, pois o aço carbono tende a se oxidar e liberar óxidos que são arrastados pela corrente de água, e ao reservatório de água, pois partículas suspensas no ambiente contaminam a água através das aberturas/bocais sem tampa. Por usa vez, a contaminação 
interna é causada por sólidos gerados pela precipitação de sais que provocam incrustação, ou seja, os sais dissolvidos na água incrustam nas paredes da tubulação e dos equipamentos. Além disso, a ação abrasiva da água pode arrastar partículas, antes incrustadas, pela corrente.

Independentemente do tipo ou da fonte de contaminação, os sólidos são extremamente prejudiciais aos circuitos de resfriamento, causando prejuízos devido à perda da eficiência de troca térmica, pois sólidos acumulados dentro de trocadores de calor aumentam a resistência à troca de calor ocasionando queda na produção, e ao desgaste de peças, já que a presença de sólidos suspensos torna a água mais abrasiva e provoca desgaste em peças como eixos rotativos, selo e rotor de bomba, etc. (Nascimento, 2004).

Com o intuito de avaliar a eficiência do sistema de tratamento da água gelada, foram escolhidas as seguintes variáveis: concentrações de sais, $\mathrm{pH}$ e sólidos suspensos.

\subsection{O Sistema de Água Gelada}

O sistema de água gelada instalado na unidade industrial tem como função resfriar a corrente de alimentação de $6^{\circ} \mathrm{C}$ para $2{ }^{\circ} \mathrm{C}$. A água gelada (AG) é utilizada em diversos pontos do processo para resfriar correntes e para complementar o processo de condensação dos vapores. Devido às condições de temperatura, é necessário o uso de anticongelante, que neste caso é o monoetilenoglicol (MEG).

A alimentação do sistema é feita com água desmineralizada produzida na unidade e o volume total do sistema é de $10 \mathrm{~m}^{3}$, com reposição eventual, visto que as perdas são desprezíveis. A circulação da AG no sistema é feita por duas bombas, uma em operação e outra reserva, para garantir a continuidade operacional do sistema.

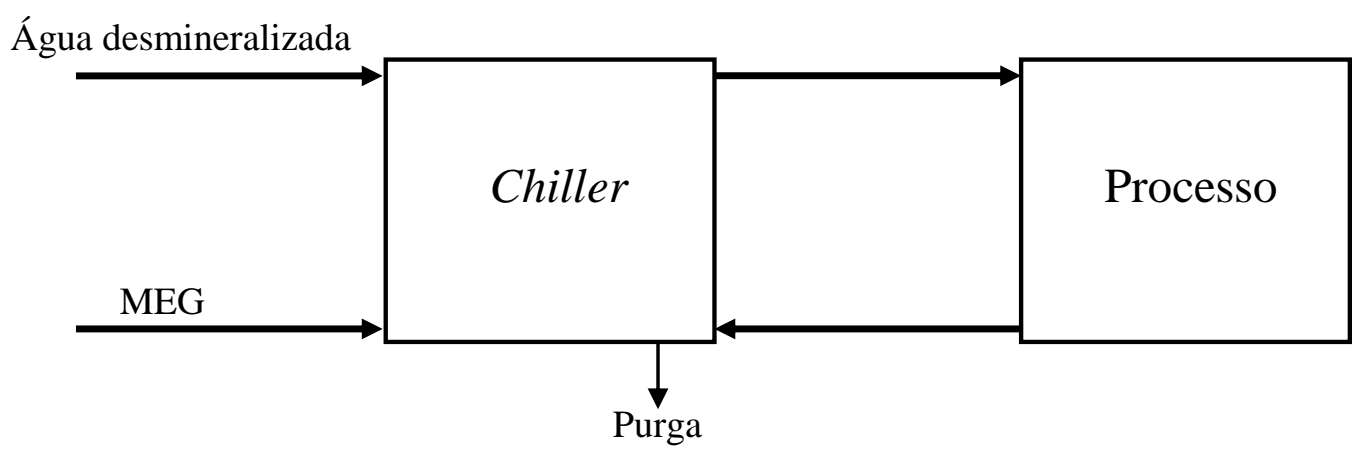

Figura 1 - Diagrama esquemático do sistema de AG.

As variáveis de processo para os quais as análises são realizadas periodicamente para o sistema de AG são: pH, cloreto, condutividade, ferro total e nitrito e realizadas de acordo com (APHA, 2012). Para a água de recirculação do sistema foram estabelecidos os limites de operação do mostrados na Tabela 1. 
Tabela 1 - Parâmetros de qualidade da água de circulação do sistema de AG.

\begin{tabular}{ccc}
\hline Variáveis & Valor & Unidade \\
\hline $\mathrm{pH}\left(25^{\circ} \mathrm{C}\right)$ & 7 a 10 & adimensional \\
Ferro Total & $<3,0$ & $\mathrm{mg} / \mathrm{L}$ \\
Nitrito & $>300$ & $\mathrm{mg} / \mathrm{L}$ \\
Condutividade & $<2500$ & $\mu \mathrm{S} / \mathrm{cm}$ \\
\hline
\end{tabular}

A água desmineralizada para alimentação do sistema deve atender as especificações mostradas na Tabela 2.

Tabela 2 - Parâmetros de qualidade da água de reposição do sistema de AG.

\begin{tabular}{ccc}
\hline Variáveis & Valor & Unidade \\
\hline $\mathrm{pH}\left(25^{\circ} \mathrm{C}\right)$ & 9 a 10 & adimensional \\
Condutividade & 10 a 20 & $\mu \mathrm{S} / \mathrm{cm}$ \\
Ciclo Operacional & 24 & $\mathrm{~h}$ \\
\hline
\end{tabular}

\section{METODOLOGIA}

Este trabalho foi desenvolvido a partir da avaliação do conjunto de dados de acompanhamento dos parâmetros físico-químicos de qualidade para o sistema de AG. As condições do sistema foram determinadas comparando o resultado das análises realizadas pelo laboratório da unidade no período entre fevereiro e dezembro de 2013, com os valores estabelecidos nas Tabela 1 eTabela 2.

As coletas de amostras foram realizadas na água de recirculação do Chiller, pois, como esse sistema opera em circuito fechado, esse ponto reúne todas as características físico-químicas proveniente do processo.

\section{RESULTADOS}

\section{1. $\mathrm{pH}$}

O pH influencia diretamente na ação dos biocidas. A baixa eficiência de ação dessas substâncias pode ocasionar maiores taxas de corrosão e incrustação nas linhas de AG e dos componentes mecânicos dos ventiladores, trocadores de calor e bombas. Além disso, a área de troca térmica no recheio sofre uma redução significativa. Águas muito alcalinas $(\mathrm{pH}>10,0)$ tendem a ser incrustantes e as águas ácidas ( $\mathrm{pH}<7,0)$, a ser corrosivas (Richter e Netto, 1991).

A Figura 2 mostra os valores de $\mathrm{pH}$ da $\mathrm{AG}$ de recirculação do chiller, que no período avaliado obteve média de 8,9 e desvio padrão de 1,3, respectivamente. É possível observar que em vários períodos do ano os valores de $\mathrm{pH}$ encontram-se fora dos limites mínimo ou máximo mostrados na Tabela 1, contribuindo para aumento da incrustação e corrosão do sistema. 


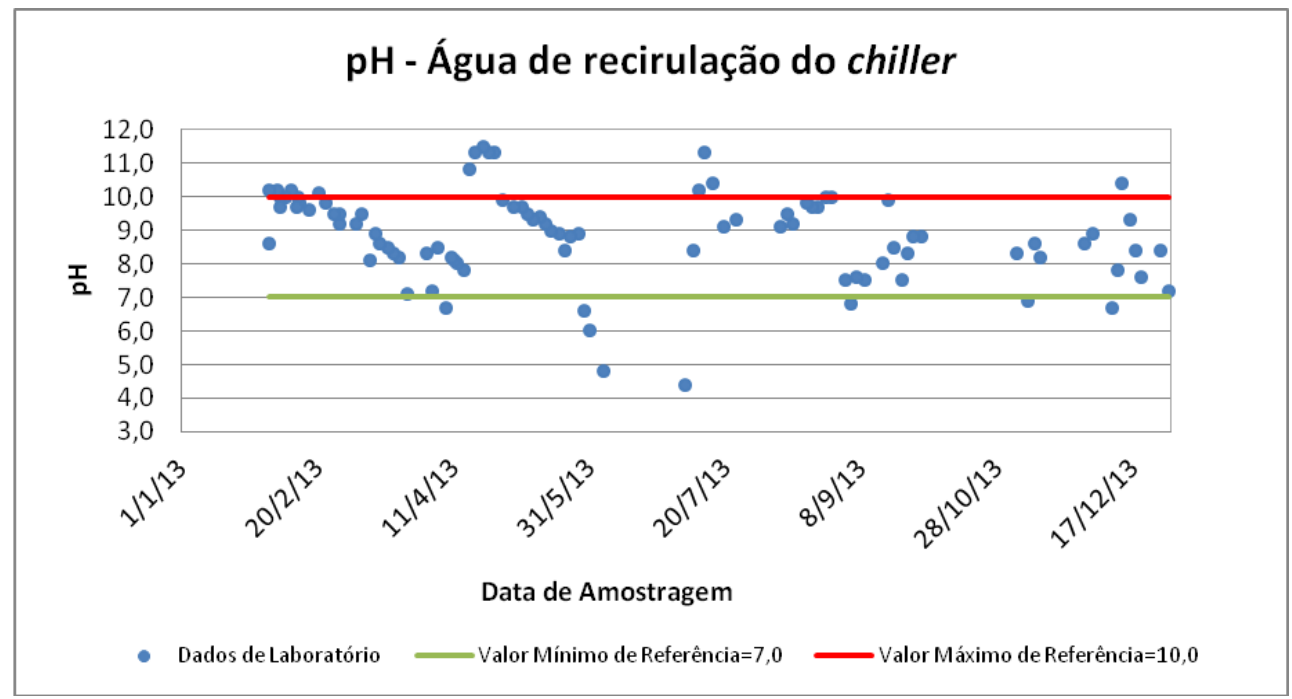

Figura 2 - Análise de pH da água de recirculação do Chiller.

\subsection{Cloreto}

A análise de cloreto realizada na água de recirculação do chiller visa conhecer os efeitos da corrosão causada por eletrólito e agente oxidante, e a consequente necessidade de dosagens dos inibidores de corrosão. Os íons cloreto também elevam a condutividade da água e destroem a camada de passivação do aço, contribuindo para o mecanismo eletroquímico da corrosão e para a formação de pites ou alvéolos, pontos de intensa corrosão localizada (Gentil, 2003).

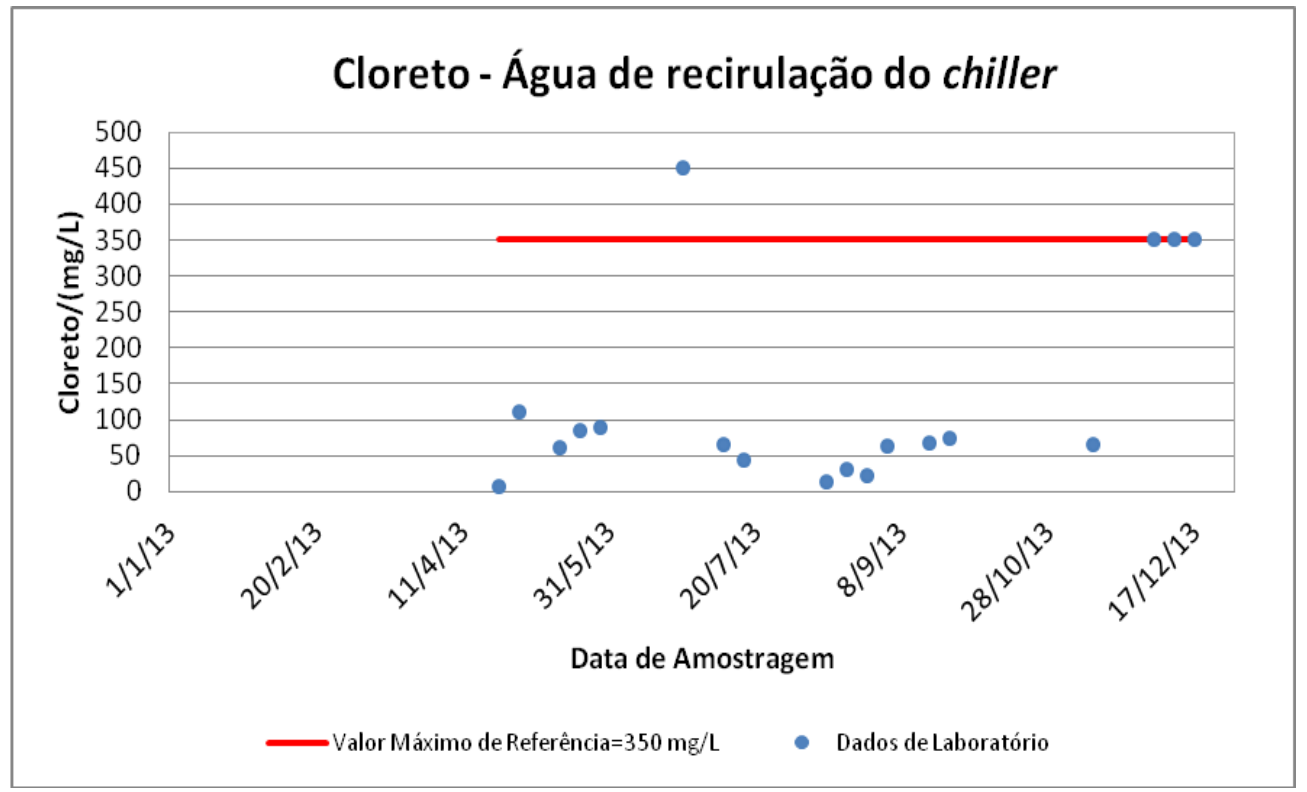

Figura 3 - Análise de Cloreto da água de recirculação do Chiller. 
As concentrações de cloreto da AG de recirculação no período estudado apresentaram média de 127,61 mg/L e desvio padrão de 140,16 mg/L, conforme mostra a Figura 3. É possível observar que a média e o desvio padrão são influenciados por alguns dados que estão iguais ou acima da concentração máxima permitida, mas $75 \%$ dos dados apresentam concentração inferior a $100 \mathrm{mg} / \mathrm{L}$, ou seja, em condições melhores que a proposta na Tabela 1.

\subsection{Condutividade}

A análise de condutividade realizada na água de recirculação do chiller, como pode ser observada na Figura 4, visou avaliar a concentração de íons totais. A elevação do valor deste parâmetro influencia diretamente no mecanismo eletroquímico de corrosão (Carvalho e Machado, 2010).

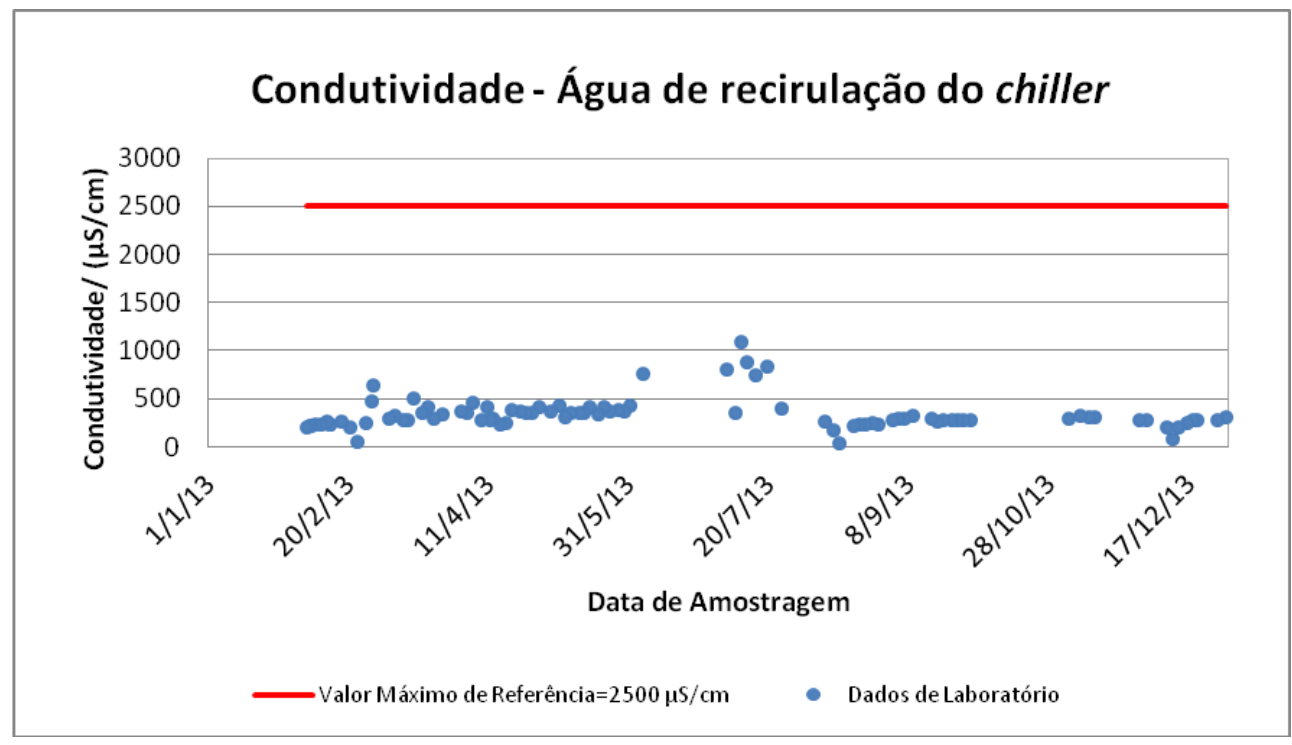

Figura 4 - Análise de Condutividade da água de recirculação do Chiller.

As análises de condutividade da água de recirculação dos chiller apresentaram média de 337,30 $\mu \mathrm{S} / \mathrm{cm}$ e desvio padrão de 165,94 $\mu \mathrm{S} / \mathrm{cm}$. Esses valores indicam que o sistema opera com concentração de íons inferior ao estabelecido na Tabela 1.

\subsection{Ferro Total}

A análise de ferro total realizada na água de recirculação do chiller visa conhecer a ocorrência de corrosão nas tubulações do sistema, o que eleva as chances de formação de pontos de elevada corrosão como pites e alvéolos (Garcia, 2009). 


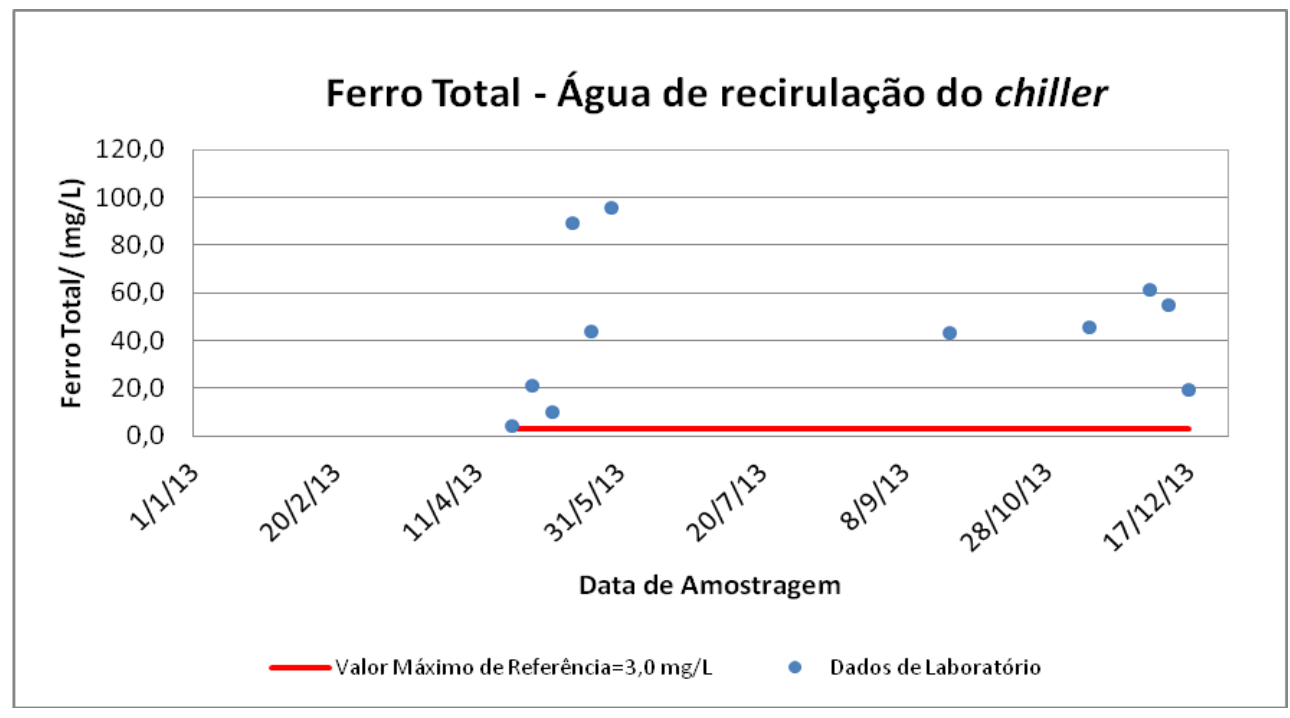

Figura 5 - Análise de Ferro Total da água de recirculação do Chiller.

As análises de ferro total na AG de recirculação do chiller mostram que o equipamento opera com a concentração de ferro total igual ou superior a concentração de referência $(3,0 \mathrm{mg} / \mathrm{L})$ durante todo o período estudado, como mostrado na Figura 5. Nota-se também um grande intervalo de tempo sem a realização de análises, por falta de reagentes. $\mathrm{O}$ sistema apresentou uma concentração média $44,44 \mathrm{mg} / \mathrm{L}$ e desvio padrão de $30,00 \mathrm{mg} / \mathrm{L}$.

\subsection{Nitrito}

A adição de nitritos ao sistema de água gelada é um mecanismo de redução da corrosão química, pois uma concentração de nitrito acima de $200 \mathrm{mg} / \mathrm{L}$ cria uma camada de proteção sobre a superfície do aço carbono (Lee et al., 2012). Desta forma, a adição de nitrito deve ser realizada periodicamente e sua concentração bem monitorada e de preferência acima do limite $(300 \mathrm{mg} / \mathrm{L})$ estabelecido pela engenharia de processo, conforme mostrado na Tabela 1.

As análises de nitrito na AG de recirculação do chiller apresentam concentração inferior à mínima estabelecida como referência $(300,0 \mathrm{mg} / \mathrm{L})$ como indicado na Tabela 1 , o que mostra a necessidade de um melhor acompanhamento nas dosagens de inibidores à base de nitritos. Nota-se também um grande intervalo de tempo sem a realização de análises por falta de reagente. $O$ desvio padrão para a concentração de nitrito está superior à média, pois a maior parte das análises apresenta valores de $1 \mathrm{mg} / \mathrm{L}$, limite inferior do método de análise. Entretanto, em uma das análises a concentração foi de 45,8 mg/L, indicando dosagem do inibidor de corrosão. 


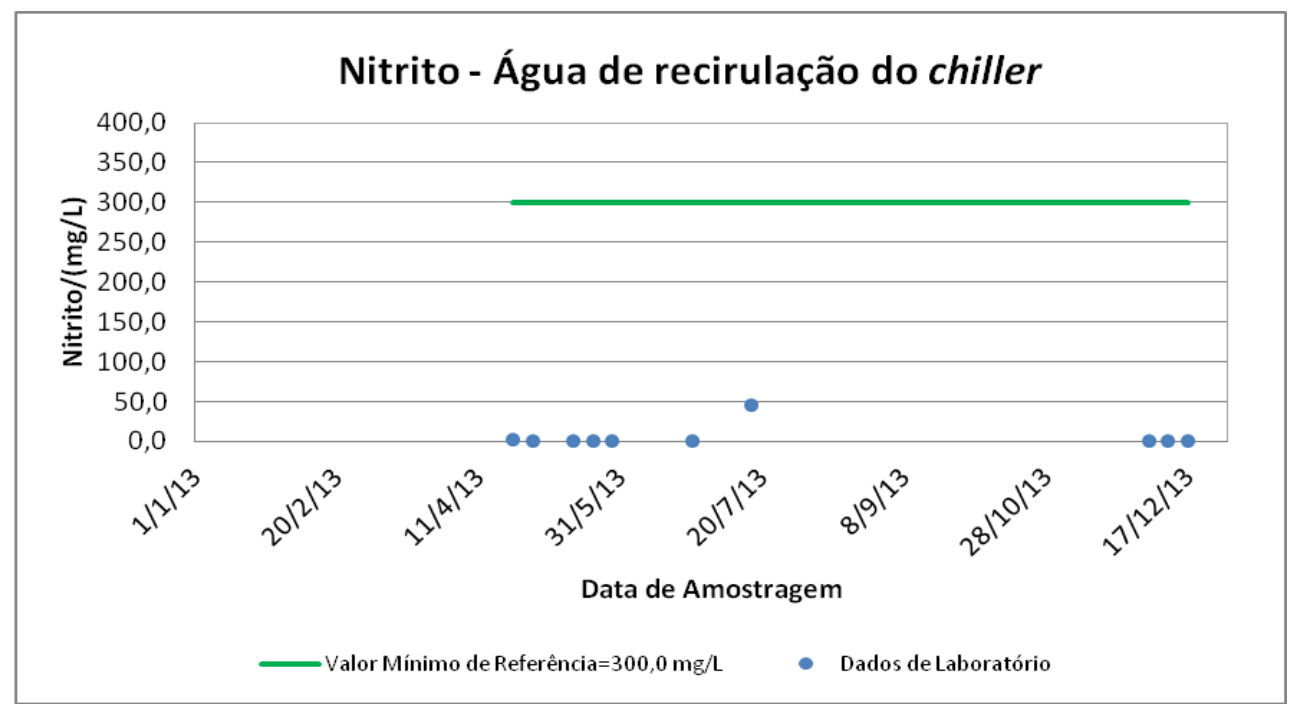

Figura 6 - Análise de Nitrito da água de recirculação do Chiller.

\section{CONCLUSÕES}

Após mais de cinco anos de operação, o acompanhamento de cada parâmetro de qualidade da água gelada foi realizado periodicamente desde fevereiro de 2013 pelo laboratório da unidade industrial. As análises mostraram que a concentração de cloreto e a condutividade atenderam aos limites de especificação. Para a análise de pH observa-se que os desvios são consideráveis, indicando um ponto a ser melhorado o que evitaria a exposição do sistema a uma condição onde existe maior risco de ocorrência de corrosão. Por essa razão, esses sistemas têm a necessidade de adição constante de inibidores de corrosão. Entretanto, durante o período estudado, a adição foi insuficiente, de forma que seu impacto pode ser confrontado com os resultados da concentração de ferro total, que por todo o período esteve acima do limite superior de referência, indicando a existência de corrosão tanto no sistema de distribuição quanto no sistema de geração de AG. Este trabalho mostrou a importância de monitorar e controlar parâmetros físico-químicos do sistema em estudo e indica que o investimento nesse acompanhamento é compensado pelo aumento da continuidade operacional e diminuição do custo de manutenção; o tratamento quantitativo desses efeitos será objeto do próximo trabalho.

\section{NOMENCLATURA}

AG - Água Gelada

MEG - Monoetilenoglicol

pH - Potencial hidrogeniônico ou potencial de hidrogênio

$\mathrm{P}+\mathrm{L}$ - Produção mais Limpa 
RMS - Região Metropolitana de Salvador

TECLIM - Rede de Tecnologia Limpas da Bahia

UFBA - Universidade Federal de Bahia

\section{REFERÊNCIAS}

APHA - AMERICAN PUPLIC HEALTH ASSOCIATION. Standard Methods for the Examination of Water and Wastewater: $22^{\text {th }}$ ed., 2012.

CARVALHO, D. D; MACHADO, B. J. F. Reuso de efluentes em torres de resfriamento - estudo conceitual: Aeroporto Internacional do Rio de Janeiro. Acta Scientiarum. Technology Maringá, v. 32, n. 3, 2010.

GARCIA, M. S. A influencia da qualidade da água de alimentação na planta de vapor. $X X I$ COPINAVAL, Montevidéu, Uruguai, 2009.

GENTIL, V. Corrosão. 4ª ed. Rio de Janeiro: LTC, 2003.

KIPERSTOK, A.; ESQUERRE, K.; KALID, R.; SALES, E.; OLIVEIRA, G. Rationalizing the Use of Water in Industry - Part 1: Summary of the Instruments Developed by the Clean Technology Network in the State of Bahia and Main Results Obtained. Journal of Environmental Protection, v. 04, n. 05, p. 486-496, 2013.

LEE, D. Y.; KIM, W. C. e KIM, J. G. Effect of nitrite concentration on the corrosion behaviour of carbon steel pipelines in synthetic tap water. Corrosion Science, v. 64, p. 105-114, 2012.

MANCUSO, P. C. S. Reuso de Água para Torres de Resfriamento. São Paulo, 2001.

RICHTER, C. A. e NETTO, J. M. A. Tratamento de Água. $1^{\text {a }}$ ed., São Paulo: Edgard Blücher Ltda, 1991.

NASCIMENTO, J. F. Avaliação de membranas de osmose inversa no tratamento de águas de purga de torres de refrigeração de indústria petrolífera com finalidade de reuso; Dissertação de Mestrado em Química - Universidade Federal Fluminense, 2004. 